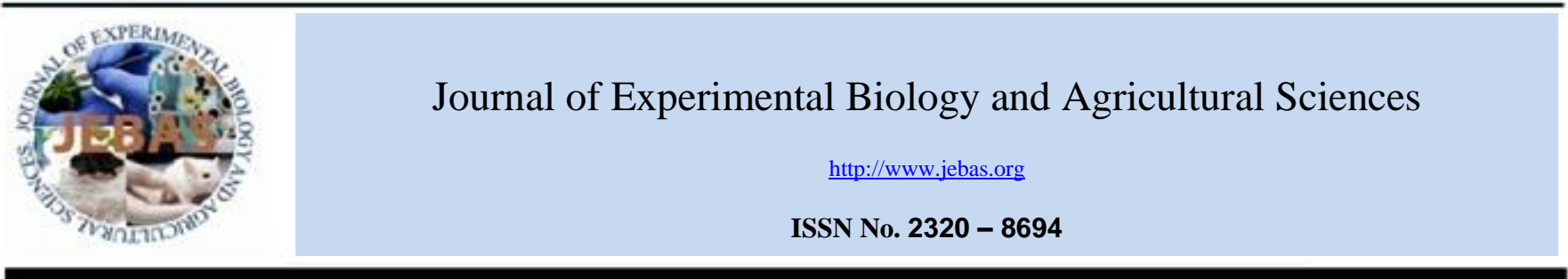

\title{
ANTIOXIDANT ENZYME AND MDA LEVEL IN THE SKIN OF ALBINO RAT UNDER THE STRESS OF ARTIFICIAL UVB RADIATION
}

\author{
Nausheen Saba Khanam, Asha Agarwal, Rafat Khan \\ Department of zoology, School of Life Sciences, Khandari campus, Dr. Bhim Rao Ambedkar University, Agra-282002, Uttar Pradesh, India \\ Received - September 20, 2019; Revision - October 31, 2019; Accepted - November 29, 2019 \\ Available Online - December 25, 2019
}

DOI: http://dx.doi.org/10.18006/2019.7(6).574.578

\section{KEYWORDS}

Antioxidant

SOD

Catalase

MDA

Albino rat

Artificial UVB radiation

Skin

\begin{abstract}
The aim of present study was to investigate the level of skin antioxidants and MDA in albino rats under stress of acute (1 day) and sub acute (30 days) artificial UVB exposure. Twenty healthy male albino rats (100-140 g) were taken for the present experiment. Rats were grouped into four sets ( 5 rats in each set). The Set A (Control set) and Set $\mathrm{A}_{1}$ (Control set) were not exposed to artificial UVB radiation while Set B was exposed to $0.44 \mathrm{~J} / \mathrm{cm}^{2}$ of artificial UVB radiation continuously for 10 hours for 1 day and Set $\mathrm{B}_{1}$ was exposed to $0.014 \mathrm{~J} / \mathrm{cm}^{2}$ of UVB radiation continuously for $20 \mathrm{~min} /$ day for 30 days. Results of study indicates a significant decrease in Catalase, SOD level and significant increase in MDA level in the skin of albino rats after acute and sub acute artificial UVB exposure. Present study also suggests decrease in SOD and Catalase content, while increase in MDA content in the skin of albino rats of Set B is more than the Set $B_{1}$. Study concluded that the UVB radiation causes damage to the antioxidant system leads to decrease in Catalase and SOD level while induces the lipid peroxidation which increases MDA level in the skin of albino rat.
\end{abstract}

* Corresponding author

E-mail: nausheenmgb@gmail.com (Nausheen Saba Khanam)

Peer review under responsibility of Journal of Experimental Biology and Agricultural Sciences.

Production and Hosting by Horizon Publisher India [HPI] (http://www.horizonpublisherindia.in/).

All rights reserved.
All the articles published by Journal of Experimental Biology and Agricultural Sciences are licensed under a Creative Commons Attribution-NonCommercial 4.0 International License Based on a work at www.jebas.org.

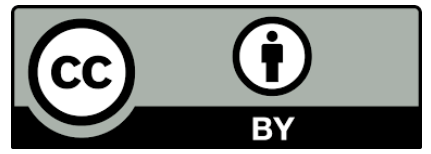




\section{Introduction}

The UV light region occurs between $100-400 \mathrm{~nm}$. This region comprises of UVC (100-280 nm), UVB (280-315 nm) and UVA (315-400 nm). Among these three, UVB has only 4-5\% of UV light region but it is most active region of sunlight and has less penetrating and more toxic nature than UVA (Svobodova et al., 2006). UVB radiation penetrates deeply into the epidermis but not into the dermis (Clydesdale et al., 2001). According to Gallagher et al. (2010) UV radiation might causes $93 \%$ of skin cancers.

Skin contains three layers i.e. Epidermis, Dermis and Hypodermis. Among these three epidermis and dermis consists various cell populations like keratinocytes, langerhans cells, melanocytes, basal cells and fibroblasts etc., while hypodermis consists adipose tissue (Bacci et al., 1998; D’Orazio et al. 2013). UVB radiation in small amount is beneficial for human health but in large amount it produces deleterious effects such as immunosuppression, inflammatory responses and carcinogenesis (Juzeniene \& Moan, 2012).

Biochemically skin made up of lipid and protein. Various antioxidants are also found in skin. Some antioxidants like SOD, Catalase, Vitamine E and Glutathione peroxidases are presented in the layers of epidermis, while some like Ascorbic acid, Uric acid and Glutathione are presented in the extracellular space of skin epidermis and dermis. Antioxidants neutralize the free radicals. These free radicals are produced by the ultraviolet radiations, cigarette smoke, air pollutants etc (Pastore \& Korkina, 2010; Cui et al., 2011; Pai et al., 2014)

Free radicals also attack lipid and produces a wide variety of oxidation products, the process is known as lipid peroxidation. The main primary product is lipid hydroperoxide (Ayala et al., 2014) and secondary products are Malonyldialdehyde (MDA), propanal, hexanal and 4-hydroxy-nonenal (4-HNE). MDA is a mutagenic product and a marker component of lipid peroxidation of omega- 3 and omega- 6 fatty acids, the poly unsaturated fatty acids (PUFA) (Esterbauer \& Cheeseman, 1990; Devasagayam et al., 2003).

SOD and Catalase are the enzymatic antioxidants, they actively scavange the reactive oxygen species (ROS) which may causes cellular oxidative stress. UVB radiations are primary etiological factors to affect the antioxidant enzyme activity (SOD and Catalase) and marker product (MDA) of lipid peroxidation (Apostolova et al., 1995; Chang \& Zheng, 2003; Ashawat et al., 2007; Badescu et al., 2012).
The present investigation highlights the biochemical changes in the skin of albino rat, Rattus norvegicus (Berkenhout) under stress of artificial UVB radiation. The biochemical changes have been assessed in terms of changes in antioxidants (SOD, catalase) and MDA level disclose the restrictions of skin in albino rats.

\section{Materials and Methods}

Twenty healthy male albino rats of 100-140 g were taken for the experiment. Rats were acclimatized (30 days) for a photoperiod of 12 hours/day at temperature $25 \pm 3^{0} \mathrm{C}$, relative humidity $55 \% \pm 5$ with proper hygiene. Albino rats were kept in clean polypropylene cages and fed with standard laboratory diet and water ad libitum.

\subsection{Experimental protocol}

Rectangular UVB radiation chamber of $90 \times 45 \times 30 \quad \mathrm{cms}$, made up of $3 \mathrm{~mm}$ thickened glass was used for present investigation. Philips F30T8 fluorescent tube light was fitted at a distance of $45 \mathrm{~cm}$ in the radiation chamber. In order to remove the hairs neatly, the hair remover cream was applied on the dorsal side of rat. The albino rats were exposed to artificial UVB radiation to different dose and different time duration vide infra. Different treatment of current study were Set AControl without UVB exposure after 1 day; Set $\mathrm{A}_{1}$ - Control without UVB exposure after 30 days; Set B- Exposed to 0.44 $\mathrm{j} / \mathrm{cm}^{2}$ of UVB radiation continuously for 10 hours for 1 day and Set $B_{1}$ - Exposed to $0.014 \mathrm{j} / \mathrm{cm}^{2}$ of UVB radiation continuously for 20 minutes/ day for 30 days. UVB radiation dose fixation was done by using Probit analysis (Finney, 1971).

\subsection{Biochemical analysis of skin}

The skin SOD was estimated by Marklund \& Marklund (1974). The skin catalase was estimated by Aebi (1984). The skin MDA was estimated by Buege \& Aust (1978). The biochemical data was accessed to statistics by the method of Fisher \& Yates (1963). Mean and unpaired t-test of biochemical changes were assessed for different exposed and unexposed rats.

\section{Results and discussion}

Skin protects animal body from the various factors of external environment. Skin serves different functions like immune response, thermoregulation, barrier response, water loss protection, insulation, excretion and toxic secretion etc. for the body. Skin is an easy target of UVB radiation and easily 
effected by the UVB radiation. UVB radiations are also obtained by the artificial source of light like UVB tube light besides natural sunlight.

In current study, various biochemical changes such as changes in the level of SOD, Catalase and MDA have been observed after artificial exposure of albino rats to UVB radiation. Present investigation highlighted that the skin toxicity is dependent on the dose and exposure duration of UVB; these results are also proved by the obtained observations from the unpaired t-test. The observations from the present study also depicted that the acute and sub acute UVB exposure are less toxic than that of long term chronic UVB exposure. Acute and sub acute UVB exposure decrease the concentration of SOD and Catalase, while increase the concentration of MDA (Table 1, 2 \& 3).

It could happen due to the more radiant energy given to the albino rats for 10 hours continuously for 1 day, because skin toxicity against UVB radiation is amount and exposure time dependent. When time duration of UVB exposure decreased to 20 minutes per day for 30 days, the decrease in SOD and Catalase content exhibited increasing trend, while increase in MDA content exhibited decreasing trend (Figure 1, $2 \& 3$ ).

Acute UVB irradiation is initiator to form reactive oxygen species which may induces cellular damage. Antioxidants like SOD can reduce the damage caused by ROS but in oxidative stressed condition the level of antioxidants is significantly reduced. UVB exposure reduces the activity of SOD (Aricioglu et al., 2001; Katiyar et al., 2008). Repeated UV radiation exposure might causes skin ageing which may lead an increase in ROS as a result of antioxidant system failure. The level of antioxidant enzymes (Catalase and SOD) was decreased and non enzyme component (MDA) was increased after UVB radiation exposure (Ashawat et al., 2007; Badescu et al., 2012).

Antioxidant activity of SOD and Catalase was lowered and lipid peroxide content was elevated in hypercholesterolemic albino rats. Various studies proved that UVB radiation caused the hypercholesterolemia in albino rats (Anila \& Vijayalakshmi, 2003; George et al., 2012; El-Shafey et al., 2015).

Biochemical changes in the SOD, MDA and catalase is held by the strike of radiant energy on the skin and the radiant energy is produced by the excitation of electrons. It is thus obvious that UVB produce damages to the skin which is proved biochemically.
Table 1 Skin Catalase content (Units/mg) in control and exposed rats.

\begin{tabular}{ccc|}
$\begin{array}{c}\text { No. of } \\
\text { Exposure } \\
\text { days }\end{array}$ & $\begin{array}{c}\text { Control set (5) } \\
\text { Range } \\
(\text { Mean } \pm \text { S. Em) }\end{array}$ & $\begin{array}{c}\text { Exposed set (5) } \\
\text { Range } \\
(\text { Mean } \pm \text { S. Em) }\end{array}$ \\
\hline 1 & $\begin{array}{c}1.48-2.41 \\
(1.80 \pm 0.195)\end{array}$ & $\begin{array}{c}0.40-1.18 \\
(0.70 \pm 0.1667)^{* * * *} \downarrow\end{array}$ \\
\hline 30 & $1.60-2.10$ & $1.38-1.58$ \\
& $(1.81 \pm 0.0996)$ & $(1.50 \pm 0.0451)^{* * *} \downarrow$ \\
\hline
\end{tabular}

S. Em- Standard error of mean; $\downarrow$ - Decrease; (5) - No. of rats; ****-Very highly significant $(p<0.001)$; *** Highly significant $(p<0.01)$

Table 2 Skin MDA content $(\mu \mathrm{mole} / \mathrm{g})$ in control and exposed rats

\begin{tabular}{|ccc|}
$\begin{array}{c}\text { No. of } \\
\text { Exposure } \\
\text { days }\end{array}$ & $\begin{array}{c}\text { Control set (5) } \\
\text { Range } \\
(\text { Mean } \pm \text { S. Em) }\end{array}$ & $\begin{array}{c}\text { Exposed set (5) } \\
\text { Range } \\
\text { (Mean } \pm \text { S. Em) }\end{array}$ \\
\hline 1 & $\begin{array}{c}5.89-9.67 \\
(7.50 \pm 0.726)\end{array}$ & $\begin{array}{c}9.88-13.97 \\
(11.82 \pm 0.841)^{* * * * \uparrow}\end{array}$ \\
\hline 30 & $\begin{array}{c}7.20-7.64 \\
(7.40 \pm 0.0857)\end{array}$ & $\begin{array}{c}7.75-8.27 \\
(8.00 \pm 0.1104)^{* * * * \uparrow}\end{array}$ \\
\hline
\end{tabular}

S. Em- Standard error of mean; $\uparrow$ - Increase; (5) - No. of rats; **** - Very highly significant $(p<0.001)$

Table 3 Skin SOD content (Units/g of protein) in control and exposed rats.

\begin{tabular}{ccc|}
$\begin{array}{c}\text { No. of } \\
\begin{array}{c}\text { Exposure } \\
\text { days }\end{array}\end{array}$ & $\begin{array}{c}\text { Control set (5) } \\
\text { Range } \\
\text { (Mean } \pm \text { S. Em) }\end{array}$ & $\begin{array}{c}\text { Exposed set (5) } \\
\text { Range } \\
\text { (Mean } \pm \text { S. Em) }\end{array}$ \\
\hline 1 & $\begin{array}{c}0.86-2.00 \\
(1.40 \pm 0.231)\end{array}$ & $\begin{array}{c}0.25-0.52 \\
(0.40 \pm 0.046)^{* * * *} \downarrow\end{array}$ \\
\hline 30 & $1.35-1.53$ & $1.01-1.30$ \\
& $(1.42 \pm 0.031)$ & $(1.20 \pm 0.052)^{* * * * \downarrow}$ \\
\hline
\end{tabular}

S. Em-Standard error of mean; $\downarrow$ - Decrease; (5) - No. of rats; **** - Very highly significant $(p<0.001)$

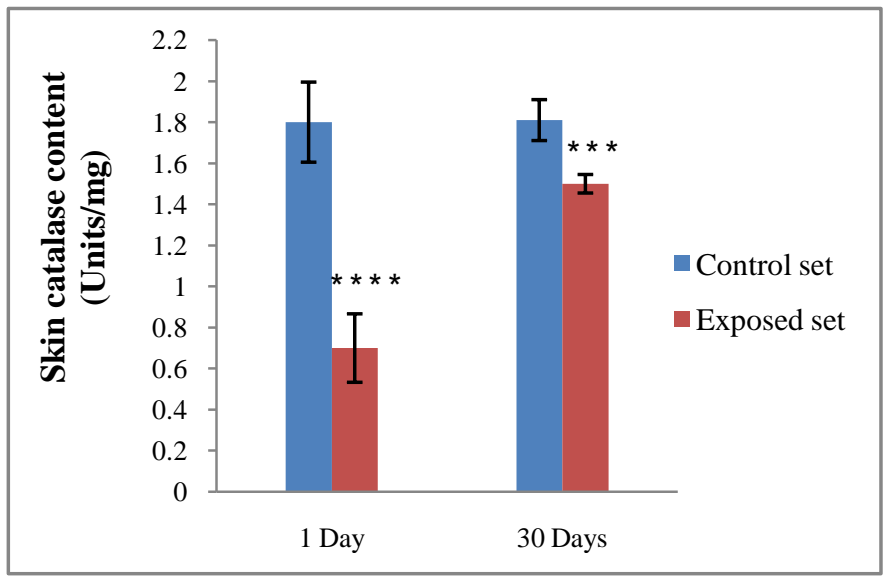

Figure1 Skin catalase content (Units/mg) in control and exposed rats. 


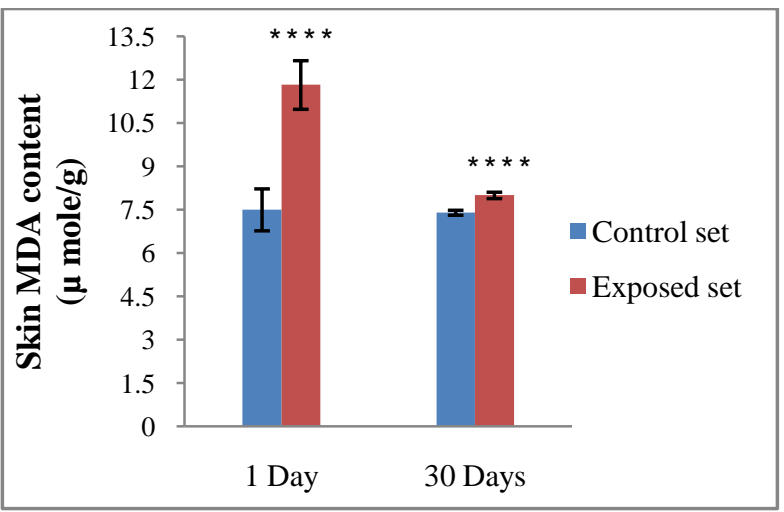

Figure 2 Skin MDA content $(\mu$ mole/g) in control and exposed rats.

\section{Conclusion}

Acute and Sub acute UVB exposure was given to the albino rats. Following biochemical analysis of rat skin, it was found that the antioxidant enzymes (SOD and Catalase) and MDA level was significantly disturbed. By exposing the albino rats with acute and sub acute UVB exposure, the antioxidant enzymes (SOD and Catalase) reduced and MDA level elevated in the skin compared to control rats. It is proved by the obtained observations after applying unpaired t-test and hypothesis was accepted with significant differences in biochemical changes which have been done by UVB exposure for different durations. Present investigation revealed the biochemical findings, which indicate pre malignant changes in the skin. Hence, the present study can play an important role to applying the preventive measures for malignancies.

\section{Conflict of interest}

No conflict of interests exist.

\section{References}

Aebi H (1984) Catalase in vitro. Methods in Enzymology 105:121-126.

Anila L, Vijayalakshmi NR (2003) Antioxidant action flavonoids from Mangifera indica and Emblica officinalis in hypercholesterolemic rats. Food chemistry 83:569-574.

Apostolova MD, Nishimura N, Tohyama C (1995) Studies on the effects of oxidative stress due to UV-B irradiation. National Institute for environmental studies, Environmental agency 151-157.

Aricioglu A, Bozkurt M, Balabanli B, Kilinc M, Nazaroglu NK, Turkozkan N (2001) Changes in zinc levels and superoxide

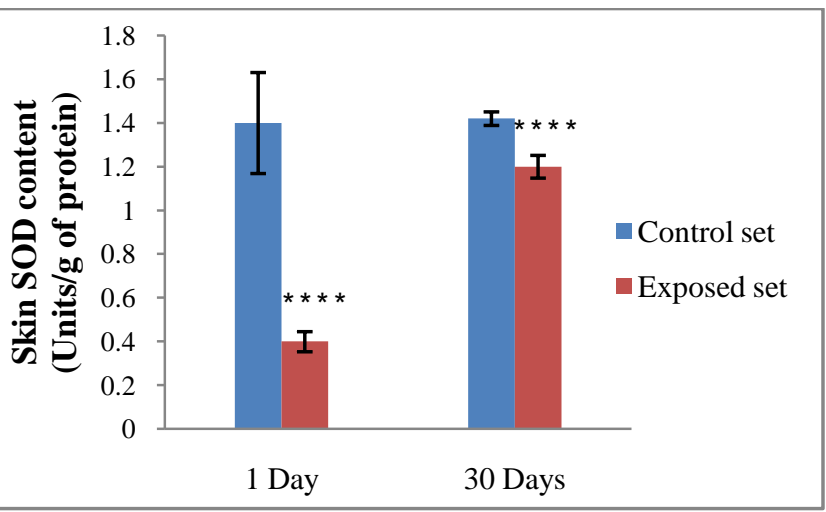

Figure 3 Skin SOD content (Units/g of protein) in control and exposed rats.

dismutase activities in the skin of acute, ultraviolet B-irradiated mice after treatment with Ginkgo biloba extract. Biological Trace Element Research 80:175-176.

Ashawat MS, Shailendra S, Swarnlata S (2007) Biochemical and Histopathological studies of herbal cream against UV radiation induced damage. Trends in Medical Research 2:135-141.

Ayala A, Munoz MF, Arguelles S (2014) Lipid peroxidation : Production Metabolism, and signaling mechanisms of malonyl dialdehyde and 4-hydroxy-2-nonenal. (Review Article). Oxidative Medicine and Cellular Longevity, Hindawi Publishing Corporation, Volume 2014, Article ID 360438, 31 pages. http://dx.doi.org/10.1155/2014/360438.

Bacci S, Romagnoli P, Streilein JW (1998) Reduction in number and morphologic alterations of langerhans cells after UVB radiation in vivo are accompanied by an influx of monocytoid cells into the epidermis. Journal of Investigative Dermatology 111 : 1134-1139.

Badescu L, Ciocoiu M, Petreus T, Neamtu M, Badescu M, Cotrutz CE (2012) Issues of epidermal senescence versus experimental Photo senescence on murine skin. Annals of the Romanian Society for Cell Biology XVII: 1:206-210.

Buege JA, Aust SD (1978) Microsomal lipid peroxidation. Methods in Enzymology 52:302-310.

Chang C, Zheng R (2003) Effects of ultraviolet B on epidermal morphology, shedding, lipid peroxide, and antioxidant enzymes in cope's rat snake (Elaphe taeniura). Journal of Photochemistry and Photobiology B : Biology. 72:79-85.

Clydesdale GJ, Dandie GW, Muller HK (2001) Ultraviolet light induced injury: Immunological and inflammatory effects. Immunology and Cell Biology 79:547-568. 
Cui LL, Liang YY, Dong FJ, Ma L, Tu Y, Liu HY, Jiang J (2011) Structure of rat skin after application of electret characterized by DSC. Journal of Physics: Conferences series 301: 012027.

D'orazio J, Jarrett S, Amaro-Ortiz A, Scott T (2013) UV radiation and the skin. International Journal of Molecular Sciences 14:12222-12248.

Devasagayam TPA, Baloor KK, Ramasarma T (2003) Methods for estimating lipid peroxidation : An analysisof merits and demerits. Indian Journal of Biochemistry and Biophysics 40_: 300-308.

El-Shafey AAM, Seliem MME, El-Zawahry SAM, Shahen EMS, Mahmoud DEM (2015) Effect of honey bee on some antioxidant enzymes and lipid profile in hypercholesterolemic male albino rats. Zagazig University Medical Journal. 21:68-78.

Esterbauer H, Cheeseman KH (1990) Dermination of aldehydic lipid peroxidation products: malonaldehyde and 4-hydroxynonenal. Methods in Enzymology 186:407-421.

Finney DJ (1971) Probit analysis, Cambridge University Press, Pp. 303.

Fisher RA, Yates (1963) Statistical tables for Biological, Agriculture and Medical Research. Longman VI edition, X+146 pp.

Gallagher RP, Lee TK, Bajdik CD, Borugian M (2010) Ultraviolet radiation. Chronic Diseases 29 supplement 1:51-68.

George KS, Elyassaki W, Wu Q, Wu S (2012) The role of cholesterol in ultraviolet light B-induced apoptosis. Journal of Photochemistry and Photobiology 88:1191-1197.

Juzeniene A, Moan J (2012) Beneficial effects of UV radiation other than via vitamin D production. Dermato-Endocrinology 4:109-117.

Katiyar SK, Meleth S, Sharma SD (2008) Silymarin, a Flavonoid from milk thistle (Silybum marianum L.), inhibits UV-induced oxidative stress through targeting infiltrating CD 11b+ cells in mouse skin. Journal of Photochemistry and Photobiology 84:266-271.

Marklund S, Marklund G (1974) Involvement of the superoxide anion radical in the auto oxidation of pyrogallol and a convenient assay for superoxide dismutase. European Journal of Biochemistry 47:469-474.

Pai VV, Shukla P, Kikkeri NN (2014) Antioxidants in dermatology. Indian journal of Dermatology 5:210-214.

Pastore S, Korkina L (2010) Redox imbalance in T cell mediated skin diseases (Review article). Mediators of Inflammation. Volume 2010 article ID 861949, 9 Pages. Hindawi Publishing Corporation.

Svobodova A, Walterova D, Vostalova J (2006) Ultraviolet light induced alteration to the skin. Biomed Papers of the Medical Faculty of University Palacky Olomouc Czech Republic 150:25-38. 